\begin{tabular}{|l|l|l|}
\hline \multicolumn{2}{|c|}{ PublisherInfo } \\
\hline \hline PublisherName & $:$ & BioMed Central \\
\hline \hline PublisherLocation & $:$ & London \\
\hline \hline PublisherImprintName & $:$ & BioMed Central \\
\hline \hline
\end{tabular}

\title{
Genetic prodrug activation in erbB-2 overexpressing breast
} cancer

\begin{tabular}{|l|l|l||}
\hline \multicolumn{2}{|c||}{ ArticleInfo } \\
\hline \hline ArticleID & $:$ & 3613 \\
\hline \hline ArticleDOI & $:$ & $10.1186 /$ bcr-1999-66591 \\
\hline \hline ArticleCitationID & $:$ & 66591 \\
\hline \hline ArticleSequenceNumber & $:$ & 33 \\
\hline \hline ArticleCategory & $:$ & Paper Report \\
\hline \hline ArticleFirstPage & $:$ & 1 \\
\hline \hline ArticleLastPage & $:$ & 4 \\
\hline \hline & $:$ & RegistrationDate : 1999-7-16 \\
\hline ArticleHistory & $:$ & OnlineDate \\
\hline \hline ArticleCopyright & $:$ & Current Science Ltd1999-7-16 \\
\hline \hline ArticleGrants & $:$ & \\
\hline \hline ArticleContext & $:$ & 1305811 \\
\hline \hline
\end{tabular}




\section{Keywords}

erb-B2 overexpression, gene therapy, Prodrug activation

\section{Introduction}

Genetic prodrug activation (GPAT) is a novel method of anti-cancer therapy. Utilising the transcriptional differences between neoplastic and non-neoplastic cells it results in neoplastic cells selectively expressing an enzymatic product of a 'suicide gene' which in turn converts a non-toxic prodrug into a cell-toxic metabolite. One such 'suicide gene' is the cytosine deaminase (CD) gene, the product of which converts the prodrug fluorocytosine (5FC) into its toxic metabolite fluorouracil (5FU).

To make CD gene expression selective to tumour cells, cellular overexpression of the erbB-2 receptor can be utilised. Overexpression of erbB-2 is seen in approximately $20-30 \%$ of breast cancers and is associated with poor response to therapy and a poor prognosis. Increased expression of erb-B2 is partly due to increased gene transcription with enhanced activity of the erbB-2 promoter. By combining a fragment of the erbB-2 promoter with the $\mathrm{CD}$ gene in a retroviral vector and transducing this into breast tumour cell lines overexpressing erbB-2, the resultant high levels of CD enzyme led to cell death when the cells were exposed to 5FC.

\section{Aims}

A Phase 1 study of the intra-tumoral injection of a plasmid containing the erbB-2 promoter fragment/ CD gene chimera into patients with cutaneous breast cancer overexpressing erbB-2 followed by systemic infusion of 5FC. Endpoints were safety, efficiency of in vivo gene transfer, the functional expression of the CD enzyme and evidence of anti-tumour activity.

\section{Comments}

This is a very interesting and important study. Gene transfer approaches to anti-cancer therapy have been intensively investigated in recent years, but this is the first reported study of this approach in breast cancer. Unfortunately, slow patient recruitment (due to highly selective entry criteria) led to only a small 
number of patients being injected, and so evidence of a consistent anti-tumour effect was unable to be detected. It is of interest that tumour regression was seen in tumour nodules injected with the study plasmid but which were not then exposed to the prodrug, suggesting either an effect of the plasmid itself on the tumour cells, or simply the tumour regression being an unrelated event. Low percentage transduction of tumour cells remains a problem for this approach and further work is required aimed at improving gene delivery thereby increasing the number of tumour cells expressing the suicide gene.

\section{Methods}

A total of 12 postmenopausal patients with multiple non-ulcerating skin metastases who had progressed despite complete conventional therapy were entered into the study. Multiple baseline investigations including full blood count (FBC), liver function tests(LFT), erythrocyte sedimentation rate (ESR), Ig levels and anti-double stranded DNA antibody levels were performed. ErbB-2 status was determined by immunohistochemistry, using two different antibodies. Membrane immunoreactivity of at least $30 \%$ was required to enter the study.

Each patient had three similar-sized lesions marked and measured. One was injected with the test plasmid, one with a control plasmid (no erbB-2 promoter/CD gene), and one lesion acted as a control. Injection occurred on day 1, biopsy on day 2, 5FC infusion on day 3 (for $48 \mathrm{~h}$ ) and further biopsy on day 7. All 12 patients received the study plasmid (dose escalated in the first four patients, then the rest at the same dose), and the first eight received $5 \mathrm{FC}$.

\section{Results}

A total of 72 patients were screened, 14 were suitable and 12 were entered. Age range was 34-78 years and duration of disease ranged from 6 to 36 months. Effect on tumour: Evidence of tumour volume reduction in four patients (two receiving plasmid and prodrug, and two receiving plasmid alone). One of these patients also demonstrated reduction in the control lesion.

Biopsy tissue: Three biopsies showed no tumour. There appeared to be no impact on the inflammatory cellular reaction following injection.

Immunohistochemistry (IHC) for CD expression: There was evidence of CD enzyme in nine patients at the day 2 biopsy, and in three of these nine at day 7 biopsy. CD immunoreactivity was completely restricted to tumour cells, in particular erbB-2 expressing tumour cells.

Detection of intralesional CD mRNA by in situ hybridisation: Positive detection occurred in four patients, all of which were also positive for CD protein on IHC. 
Determination of CD activity by thin layer chromatography (TLC): In the day 2 biopsies, three patients demonstrated evidence of CD enzyme activity. There appeared to be no correlation between CD immunoreactivity and CD enzyme activity.

Safety:There was no evidence of either local or systemic toxicity secondary to the plasmid injections, and no toxicity due to the 5FC infusion. There was no double stranded DNA antibody formation.

\section{Discussion}

This study demonstrates that the GPAT technique is feasible and safe. The plasmid can be successfully transduced into tumour cells, the ?suicide gene? expressed selectively in these cells, and the resulting expressed enzyme can activate a prodrug. Overall, there was evidence of gene transfer and expression in 11 of 12 patients.

\section{References}

1. Pandha HS, Martin LA, Rigg A, Hurst HC, Stamp GW, Sikora K, Lemoine NR: Genetic prodrug activation therapy for breast cancer: A Phase 1 clinical trial of erbB-2 directed suicide gene expression. J Clin Oncol. 1999, 17: 2180-2189. 